\title{
Analysis of Integrin Expression on Oligodendrocytes during Axo-Glial Interaction by Using Rat-Mouse Xenocultures
}

\author{
Christopher E. Shaw, ${ }^{1}$ Richard Milner, ${ }^{2}$ Alastair S. Compston, ${ }^{1,3}$ and Charles ffrench-Constant ${ }^{2,3}$ \\ 'University of Cambridge Neurology Unit, Addenbrookes' Hospital, Cambridge CB2 2QQ, United Kingdom, 2Wellcome/ \\ CRC Institute of Developmental Biology and Cancer, Cambridge CB2 1 QR, United Kingdom, and ${ }^{3 M R C}$ Cambridge \\ Center for Brain Repair, University Forvie Site, Cambridge CB2 2QQ, United Kingdom
}

To analyze the expression of cell-surface molecules on neurons or glia during myelination, we have developed a xenotypic coculture system in which mouse oligodendrocytes interact with rat dorsal root ganglion neurons. The axo-glial interactions in these cultures promote oligodendrocyte precursor cell proliferation, survival, and differentiation as in vivo, thus supporting the validity of the xenocultures as a model system to study myelination in which the molecules on the neurons or the glia can be distinguished using species-specific antibodies. We examined the expression of integrins, the major family of cellsurface extracellular matrix receptors, on oligodendrocytes during the early stages of myelination and found that, unlike
Schwann cells, oligodendrocytes do not express $\alpha 6 \beta 4$ in association with myelin sheath formation. The pattern of integrin expression observed on oligodendrocytes in these cultures is similar to that seen in oligodendrocytes that differentiate in purified cultures, and it comprises $\alpha 6 \beta 1, \alpha \vee \beta 5$, and an as yet uncharacterized $\alpha \mathrm{v}$-associated $\beta$ subunit of $80 \mathrm{kDa}$. Changes in integrin expression associated with differentiation, therefore, do not depend on axonal contact, and $\beta 4$ is not required for myelin sheath formation, although its expression may contribute to the individual properties of oligodendrocytes and Schwann cells.

Key words: oligodendrocyte; Schwann cell; neuron; cocultures; integrin; differentiation; myelination
Myelination represents a striking example of cell-cell interaction and cell differentiation during development of the CNS. Precise control of oligodendrocyte precursor migration, proliferation, and differentiation is required before axo-glial contact and the formation of the multilamellar compacted myelin sheath. Growth factors regulate migration, proliferation, differentiation, and survival of oligodendrocytes and their precursors (Noble et al., 1988; Armstrong et al., 1990; Barres et al., 1992; Louis et al., 1993; McKinnon et al., 1993; Pfeiffer et al., 1993; Barres and Raff, 1994). Less attention has been paid to another group of extracellular cues, extracellular matrix molecules (ECM), despite evidence that these molecules play significant instructive roles elsewhere in development (Adams and Watt, 1993; DeSimone, 1994; Hynes, 1994). ECM molecules such as fibronectin, laminin, vitronectin, thrombospondin, and tenascin are expressed in developing white matter during development (Chun and Shatz, 1988; McLoon et al., 1988; O'Shea et al., 1990; Neugebauer et al., 1991; Bartsch et al., 1992a,b), and oligodendroglia express a limited repertoire of integrins, the major class of ECM receptors, during development (Malek-Hedayat and Rome, 1994; Milner and ffrench-Constant, 1994). In addition, arginine-glycine-aspartic acid peptides that block some integrin-ECM interactions perturb oligodendrocyte differentiation and myelin gene expression (Cardwell and Rome, 1988; Malek-Hedayat and Rome, 1994), illustrating a significant role for ECM molecules in myelination.

Received Aug. 28, 1995 ; revised Nov. 7, 1995; accepted Nov. 10, 1995

This research was funded by the Welloome Trust and the New Zcaland Health Board Rescarch Council. C.ES holds a Welloome Trust overseas research fellowship. R.M. holds a Wellcome prize fellowship, and C.ff-C. is a Wellcome Trust senior clinical fellow.

Correspondence should be addressed to C. ffrench-Constant, Wellome/CRC Institute of Developmental Biology and Cancer, Tennis Court Road, Cambridge CB2 1QR, UK.

Copyright 1996 Society for Neuroscience $0270-6474 / 96 / 161163-10 \$ 05.00 / 0$
The expression of integrins is regulated during development, consistent with an instructive role for integrins in controlling oligodendroglial proliferation and differentiation (Milner and ffrench-Constant, 1994). These earlier studies of oligodendroglial integrins, however, were based on results obtained in oligodendrocytes cultured without neurons. Schwann cells, like oligodendrocytes, express $\alpha 6 \beta 1$ before myelin formation, but axonal contact and wrapping is associated with a switch in $\alpha 6$ association from $\beta 1$ to $\beta 4$ (Einheber et al., 1993; Feltri et al., 1994; Niessen et al., 1994a). The $\beta 4$ and $\beta 1$ cytoplasmic domains are different (Hogervorst et al., 1990; Suzuki and Naitoh, 1990; Tamura et al., 1990), and this might have important functional consequences for the Schwann cell. This result emphasizes the importance of also establishing the regulation of oligodendrocyte integrins during axo-glial interactions. To do this, we have used a xenotypic coculture system in which mouse oligodendroglia interact with rat dorsal root ganglia neurons. This system allows the use of antibodies specific to mousc or rat integrins to distinguish glial and neuronal integrins. By using such species-specific anti-integrin monoclonal antibodies in immunoprecipitation experiments, we have shown that, unlike Schwann cells that express $\alpha 6 \beta 4$ at the onset of myelination, the repertoire of integrins expressed on oligodendrocytes is not influenced by the presence of neurons.

\section{MATERIALS AND METHODS}

Tissue culture. Sensory neuron cultures were established by modifying the technique described hy Kleitman et al. (1991). For immunocytochemistry, cultures were grown on sterile $19 \mathrm{~mm}$ coverslips coated with $0.01 \%$ poly-1)-lysine (Sigma, St. Louis, MO) and subsequently coated with rat tail collagen before being placed in 12-well plates (Nunc, Naperville, IL) For transmission electron microscopy, aclar dishes were prepared and coated with poly-D-lysine and collagen and placed in 6-well plates (Nunc). For immunoprecipilation, 6-well plates (Nunc) were coated with 0.5 $\mathrm{mg} / \mathrm{ml}$ poly-DL-ornithine (Sigma) and $1 \mathrm{mg} / \mathrm{ml}$ laminin (Sigma). Dorsal root ganglia (DRG) were dissected from embryonic day 15 rats and 
dissociated with $0.1 \%$ trypsin (Sigma) for $20 \mathrm{~min}$ on a heated shaker at $37^{\circ} \mathrm{C}$ after which $0.001 \%$ DNase (Sigma) was added for $3 \mathrm{~min}$. The cells were triturated in 1\% Albumax (Gibco, Gaithersburg, MD), $0.001 \%$ DNase (Sigma), and $0.05 \%$ trypsin inhibitor (Sigma), forming a single cell suspension. The cells were diluted with DMEM with $10 \%$ fetal calf serum (FCS) and $1 \%$ penicillin/streptomycin (all Gibco) until a density of $1.5 \times$ $10^{6} \mathrm{cells} / \mathrm{ml}$ was achicved, and then $50 \mathrm{ng} / \mathrm{ml}$ nerve growth factor (NGF) (Bochringer Mannheim, Indianapolis, IN) was added. These cells were then plated onto coverslips, aclar dishes, and 6-well plates. The next day, the medium was changed to a defined medium, termed N2B3 (Levison and McCarthy, 1991). This medium consisted of a 1:1 mixture of DMEM and Ham's F12 supplemented with $5 \mu \mathrm{g} / \mathrm{ml}$ bovine insulin, $50 \mu \mathrm{g} / \mathrm{ml}$ human transferrin, $100 \mu \mathrm{g} / \mathrm{ml}$ bovine serum albumin (BSA) $\mathrm{V}, 6.2 \mathrm{ng} / \mathrm{ml}$ progestcronc, $16 \mu \mathrm{g} / \mathrm{ml}$ putrescine, $5 \mathrm{ng} / \mathrm{ml}$ sodium selenite, $400 \mathrm{ng} / \mathrm{ml} \mathrm{T} 3$, $400 \mathrm{ng} / \mathrm{ml}$ thyroxine $400,4 \mathrm{mM}$ l-glutamine (all Sigma), and $0.5 \%$ FCS. Uridine $\left(10^{5} \mathrm{M}\right)$ and the antimitotic agent 5-fluoro 2 'deoxyuridine $(5 \mathrm{FU})\left(10^{5} \mathrm{M}\right), 1 \%$ penicillin/streptomycin, and $50 \mathrm{ng} / \mathrm{ml} \mathrm{NGF}$ were then added. This N2B3 conlaining 5FU and DMEM witl $10 \%$ FCS was alternated every $2-3$ d for $2-3$ weeks until the dividing fibroblasts and Schwann cells had been eliminated and $>95 \%$ neuronal purity had been achieved, after which the medium was changed to N2B3 with NGF.

Purified oligodendrocyte progenitors were prepared from forebrain cultures grown from neonatal rat and mouse brain that were then shaken to dislodge oligodendroglial cells, as described by McCarthy and Do Vellis (1980). The forebrain cultures were grown in $10 \%$ horse serum (HS) rather than $10 \%$ FCS, which improves mouse cell survival. A described previously, the purity of these oligodendroglial cultures is at least $95 \%$ (Milner and ffrench-Constant, 1994). These cells were plated onto poly-[-lysine- or collagen-coated coverslips or the purificd DRG cultures at a density of $1 \times 10^{\prime}$ cells $/ \mathrm{ml}$. They were maintained thereafter in N2B3 with $1 \%$ HS to promote oligodendrocyte differentiation and myelination. Integrins were analyzed by immunoprecipitation after $10 \mathrm{~d}$ in coculture.

Schwann cells were prepared from neonatal mice and rats using the method of Brockes et al. (1979). They were plated onto cultures at a density of $1 \times 10^{6} \mathrm{cells} / \mathrm{ml}$ and maintained in an unmelinated state in N2B3 or changed to a medium of DMEM with $10 \% \mathrm{HS}$. $5 \%$ human placental serum, and $50 \mu \mathrm{g} / \mathrm{ml}$ ascorbic acid (Sigma) to allow myelination. Coculture medium contained $\mathrm{NGF}$ at $50 \mathrm{ng} / \mathrm{ml}$ and was changed every 3-4 d. Cell populations enriched for astrocytes were obtained by using the basal cell layer remaining in the forebrain cultures after oligodendroglia had been removed by shaking, as described above.

Immunofluorescence microscopy. Glial development was examined by double labeling cultures with either anti-galactocerebroside (anti-GalC) (Ranscht et al., 1982) or rat monoclonal anti-myelin basic protein (antiMBP) (Serotec, Oxford, UK) followed by polyclonal rabbit anti-cow glial fibrillary acidic protein (anti-GFAP; Dako, Carpinteria, CA). The secondary antibodies that were used were anti-mouse fluorescein isothiocyanate (FITC; Sigma), anti-rat FITC, anti-rabbit rhodamine (both from Caltag, San Francisco, CA), or biotinylated anti-mouse followed by streptavidin-labeled FITC or Texas Red (all from Vector, Burlingame, CA). To visualize the surface antigen, GalC ${ }^{+}$cells were stained live at $37^{\circ} \mathrm{C}$ for $20 \mathrm{~min}$, fixed with $2 \%$ paraformaldehyde, permeabilized with alsolute methanol at $-20^{\circ} \mathrm{C}$, and blocked with $10 \%$ goat serum beforc the secondary antibodies and the antibodies against the cytoplasmic antigens MBP and GFAP were added. Controls were performed using an identical method but without the primary antibody. Oligodendrocyte survival was assessed by the addition of $5 \mu \mathrm{g} / \mathrm{m}$ l propidium iodide for 30 sec, washing with medium, and staining with antibody to GalC. Propidium iodide exclusion was used to identify live cells. All coverslips were mounted in Gurr aqueous mountant (BDH, Poole, UK) and observed under phase and fluorescence using a Zeiss IM35 inverted microscope (Thornwood, NY). Results are expressed as mean \pm SEM of at least three scparate experiments.

lroliferation assays. Rat and mouse oligodendrocyte progenitor proliferation was assessed by the addition of $7 \mathrm{mCi}$ of tritiated thymidine to the cultures for $12 \mathrm{hr}$. Cells were then harvested with $1 \%$ SDS and $1 \mathrm{M}$ $\mathrm{NaOH}$, and triplicate samples were added to scintillation fluid and analyzed on a beta counter. To confirm that the dividing cells were of the oligodendrocyte progenitor lineage, bromodeoxyuridine (BrdU) was added to the cultures for $24 \mathrm{hr}$, after which cultures were stained live with monoclonal anti-GD3 antibody to label oligodendrocyte precursor cells (Levi et al.. 1987; Curtis et al., 1988), fixed and permeabilized with methanol, treated with $2 \mathrm{M} \mathrm{HCl}$ for $40 \mathrm{~min}$, and labeled with anti-BrdU antibodies (Serotec) to detect BrdU incorporated by dividing cells.
Detemination of axo-glial association. To determine whether oligodendrocyte precursors or oligodendrocytes preferentially bound to axons cells were stained with the monoclonal antibody A2B5 (which labels precursor cells and newly differentiated oligodendrocytes) (Raff et al., 1983) or anti-GalC (which labels oligodendrocytes) (Ranscht ct al., 1982) at 4 hr or $3 \mathrm{~d}$ after plating onto DRG neurons. Fields with a low density of neuronal processes at the periphery of the culture were chosen, and cells were scored based on whether they were in contact with a neuronal process.

Transmission electron microscopy. To determine the ultrastructural association of the oligodendrocyte myelin membranc with axons, transmission electron microscopy was performed after 2-4 weeks of coculture. Cultures were fixed in $2.5 \%$ glutaraldehyde in $0.1 \mathrm{M} \mathrm{1,4-piperazinedicthanesulfonic}$ acid (PIPES) buffer containing $3 \mathrm{mM} \mathrm{CaCl}_{2}$, pH 7.4, for $2 \mathrm{hr}$ at room temperature followed by rinsing in $0.1 \mathrm{M}$ PIPFS buffer. Osmication was carried out in $1 \%$ osmium tetroxide in $0.1 \mathrm{M}$ PIPES buffer with $3 \mathrm{~mm} \mathrm{CaCl}$, $\mathrm{pH} 7.4$, for $1 \mathrm{hr}$ followed by dehydration in ascending concentrations of ethanol. Cultures were embedded in Araldite epoxy resin, and selected sections were cut at $50 \mathrm{~nm}$ using a Reichert Jung Ultracut $E$ and then double stained with uranyl acetate and lead citrate before viewing in a Philips EM400 transmission electron microscope (Cheshire, CT).

Cell-surface labeling and immunoprecipitation. Cell-surface molecules were labeled with biotin by removing growth media, washing the cell layer twice with PBS, and then labeling with $0.1 \mathrm{mg} / \mathrm{ml}$ NHS-LC-Biotin (Pierce, Rockford, IL) in PBS at $37^{\circ} \mathrm{C}$ in $7.5 \% \mathrm{CO}_{2}$ for $1 \mathrm{hr}$. Cell monolayers werc then washed three times with cell-wash buffer $(50 \mathrm{~mm}$ Tris- $\mathrm{HCl}, \mathrm{pH} 7.5$, $0.15 \mathrm{M} \mathrm{NaCl}, 1 \mathrm{mM} \mathrm{CaCl}$, and $1 \mathrm{mM} \mathrm{MgCl}_{2}$ ) and harvested with a rubber policeman before being washed twice more in suspension. Cells were then lysed in $1 \%$ Nonidet P40 exiraction buffer (cell-wash huffer plus 300 $\mu \mathrm{g} / \mathrm{ml}$ phenylmethyl sulfonyl fluoride, $1 \mu \mathrm{g} / \mathrm{ml}$ pepstatin $\mathrm{A}, 2 \mu \mathrm{g} / \mathrm{ml}$ aprotinin, and $4 \mu \mathrm{g} / \mathrm{ml}$ leupeptin) for $30 \mathrm{~min}$ on ice, followed by trituration and centrifugation at $14,000 \mathrm{rpm}$ at $4^{\circ} \mathrm{C}$ to remove the insoluble fraction. The supernatants were then precleared by two sequential $2 \mathrm{hr}$ incubations with $30 \mu$ of protein A-Sepharose (Pharmacia. Piscataway, $\mathrm{NJ}$ ) and $4 \mu \mathrm{l}$ of nonimmune rabbit serum/ml cell lysate. Immunoprecipitations were carried out overnight at $4^{\circ} \mathrm{C}$ on a rotating platform using 250 $\mu l$ of cell lysate. The $\alpha v$ antiserum was used at $1: 250$, whereas the monoclonal antibodies were used at the following concentrations: GoH3 (supernatant) 4:250; 346-11A (supernatant) 4:250; FII (ascites) 1:250; and P3G2 (ascites) 1:250. Rabbit anti-rat or rabbit anti-mouse antisera were also added to the tubes in which rat or mouse monoclonal antibodies were used. This linking antiserum was used at the same concentration as the primary antisera $(1: 250)$. The immune complexcs were collected by incubation with $30 \mu \mathrm{l}$ of protein A-Sepharose beads for $2 \mathrm{hr}$, after which the beads were extensively washed five times in immunoprecipitation wash buffer (identical to the cell-wash buffer except for $0.5 \mathrm{M} \mathrm{NaCl}$ and the addition of $0.1 \%$ Tween-20). Integrins were separated from the beads by boiling in nonreducing SDS sample buffer for 5 min before analysis by SDS-PAGE on a $7.5 \%$ resolving gel and $4 \%$ stacking gel under nonreducing conditions. Proteins were then electroblotted for 3 hr onto nitrocellulose (Hybond-C, Amersham, Buckinghamshire, UK), blocked overnight with $3 \%$ BSA in Tris-buffered saline $(10 \mathrm{~mm}$ Tris- $\mathrm{HCl}, 0.15 \mathrm{NaCl}$, $\mathrm{pH} 8.0$ ) containing $0.1 \%$ Tween-20, and detected with streptavidinhorseradish peroxidase (ECL detection system, Amersham) for $/ \mathrm{hr}$, according to the manufacturer's instructions. The monoclonal antibodies used in the immunoprecipitations were gifts from the following donors: CroH3 (rat IgGi, anti-r6) from Dr. Arnoud Sonnenberg (Amsterdam, The Netherlands) (Sonnenberg et al., 1987; Hogervorst et al., 1993); 346-11A (rat IgGl, anti- $\beta 4$ ) from Dr. Steve Kennel (Oak Ridge, TN) (Kennel et al., 1989), and P3G2 (mouse IgG1, anti- $\alpha v \beta 5$ ) from Dr. David Cheresh (Scripps Research Institute, San Diego, CA) (Wayner et al., 1991). The polyclonal rabbit anti- $\alpha v$ antisera was a gift from Dr. Guido Tarone (Milan, Italy).

\section{RESULTS}

\section{Neurons influence oligodendroglial behavior in xenotypic cultures}

To validate the use of the xenotypic oligodendroglia-DRG coculture system as a model for the study of neuron-glia interactions, we examined proliferation, survival, and differentiation of mouse or rat oligodendrocyte precursors added to established cultures of rat DRG within which an cxtensive network of neuronal processes had developed. 


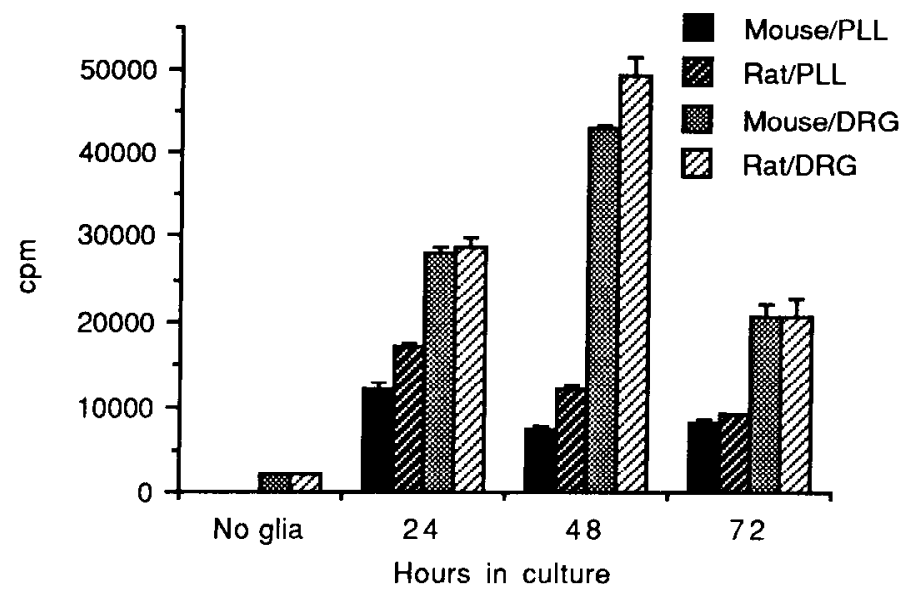

Figure 1. Stimulation of oligodendroglial proliferation by neurons. Oligodendrocyte precursors from mouse and rat were cultured for up to 3 d in the presence and absence of rat neurons (DRG and PLL, respectively) and then given a $12 \mathrm{hr}$ pulse of tritiated thymidine beforc analysis. Mouse/PLL is indicated by black bars; rat/PLL is indicated by bars with thick diagonal lines; mouse/DRG is indicated by shaded bars; and rat/DRG is indicated by bars with thin diagonal lines. Note that the presence of DRG causes increased cell proliferation within both rat and mouse oligodendroglial cells after 1,2 , and $3 \mathrm{~d}$.

\section{Proliferation}

When oligodendrocyte precursors from rat or mouse brain were plated onto rat DRG axon networks, they proliferated at a higher rate than those plated on poly-L-lysine (PLL) in the absence of neurons, as measured by tritiated thymidine uptake (Fig. 1). The influence of the neurons on oligodendroglial proliferation was similar regardless of whether the oligodendroglia were from rat or from mouse (Fig. 1). Proliferation of oligodendrocyte precursors of either species could be revealed directly in double-labeling immunofluorescence studies by showing that cells expressing the oligodendrocyte precursor marker GD3 had incorporated BrdU added for $24 \mathrm{hr}$ to the culture (Fig. 2). Quantitative analysis of these double-labeled cells confirmed the enhanced proliferation seen in the presence of neurons (Fig. 3).

\section{Survival}

Oligodendroglial cells require defined survival factors to prevent programmed cell death when grown in purified cultures (Barres and Raff, 1994). We found that the mouse oligodendrocytes that developed from precursor cells plated in the absence of neurons and identified by antibodies against GalC died in a defined medium containing $1 \%$ HS. As assessed by propidium iodide exclusion, all cells were dead within $8 \mathrm{~d}$ (Fig. 4). In contrast, when the same cells were grown under identical culture conditions but in the presence of rat DRG neurons, most oligodendrocytes survived beyond $30 \mathrm{~d}$ in culture (Fig. 4).

\section{Differentiation}

In agreement with previous studies (Raff et al., 1983; Levi et al., 1987; Behar et al., 1988; Hardy and Reynolds, 1991), we found that oligodendrocyte precursors of both species grown on PLLcoated coverslips in defined medium differentiated predominantly into oligodendrocytes expressing GalC and MBP, whereas a minority become type 2 astrocytes expressing GFAP. Mouse and rat progenitors differentiated rapidly in the absence of neurons such that by day 4 in secondary culture, $71 \pm 4 \%$ of mouse cells and 54 $\pm 2 \%$ of rat cells expressed GalC, whereas $<20 \%$ of the cells had differentiated into astrocytes (Fig. 5). The percentage of cells cxpressing GFAP increased sharply in the mouse cells after $4 \mathrm{~d}$, reflecting the lack of mouse oligodendrocyte survival in our culture conditions described above. The minor species difference in the rate of differentiation into oligodendrocytes was also seen in cocultures, but there was a significant delay in differentiation for both species such that after $4 \mathrm{~d}$ in coculture only $42 \pm 4 \%$ of mouse cells and $26 \pm 5 \%$ of rat cells cxpressed GalC (Fig. 5). Subsequent differentiation proceeded with sequential GalC and MBP expression. By day 8, a majority of cells had differentiated into oligodendrocytes, and there was little difference between the proportion of mouse cells and rat cells expressing GalC (61 \pm 4 and $62 \pm 3 \%$, respectively; Fig. $5 C$ ).

\section{Establishment of axo-glial contact}

We next examined the cell-cell interactions between mouse and rat neurons in these cultures. A majority of mouse oligodendroglial cells were in contact with axons. More than $95 \%$ of all A2B5-expressing cells at $4 \mathrm{hr}$ (Fig. $6 A, B$ ) and $>95 \%$ of all GalCexpressing cells at $3 \mathrm{~d}$ (Fig. $6 C, D$ ) were adherent to neuronal processes in low axon density fields. As oligodendrocytes differentiated, their processes showed strict alignment along axonal bundles, as shown by GalC (Fig. $7 A, B$ ) and MBP-staining (Fig. $7 C, D$ ). This suggested a strong oligodendrocyte preference for retaining neuronal contact during process extension. Examination by electron microscopy of cocultures after 4 weeks in vitro showed compacted myelin sheaths around neuronal processes, demonstrating that mouse oligodendrocytes in these cultures form myelin (Fig. $8 A, B$ ). These myelin sheaths were extremely rare, however, and were found around $<1 \%$ of axons.

\section{Investigation of integrin expression on oligodendroglia in contact with axons}

These results show that rat neurons influence the proliferation, survival, and differentiation of mouse oligodendroglial cells and that myelin sheath formation can occur in these cultures. Having confirmed the validity of the xenoculture system, we analyzed the two classes of integrins expressed on isolated oligodendrocytes ( $\alpha 6$ and $\alpha v$ ), taking advantage where possible of antibodies specific to mouse or rat integrins so as to distinguish glial and neuronal integrins.

\section{$\alpha 6$ Integrins}

In a previous study, we used the rat monoclonal antibody $\mathrm{GoH} 3$ to identify $\alpha 6$ integrins on oligodendroglial cells (Milner and ffrench-Constant, 1994). The GoH3 antibody recognizes mouse but not rat integrins. This species specificity is confirmed in Figure 9, which shows that GoH3 recognizes $\alpha 6$ integrins on mouse astrocytes but not on rat DRG neurons. Immunoprecipitations performed with the GoH3 antibody on lysates from established cocultures (in which the oligodendroglial cells had been plated at least $10 \mathrm{~d}$ previously) show that $\alpha 6$ integrins are expressed in this system (Fig. 9). Because GoH3 does not recognize $\alpha 6$ on the rat DRG neurons, the observed $\alpha 6$ is derived from mouse oligodendrocytes. Just as with oligodendrocytes grown in purified cultures, two distinct forms of the $\alpha 6$ subunit were seen, as shown by two sharp bands separated by $\sim 10 \mathrm{kDa}$ on nonreducing gels. In contrast to mouse oligodendrocytes grown in purified cullures that show a dominant upper band, however, the lower molecular weight band of $\alpha 6$ was consistently shown to predominate on oligodendrocytes grown in neuronal coculture ( $n=8$; Fig. 9).

Schwann cells also express $\alpha 6$ integrins but switch the expression of associated $\beta$ subunits from $\alpha 6 \beta 1$ to $\alpha 6 \beta 4$ at the start of myelin sheath formation on DRG neurons (Einhaber et al., 1993; 
Figure 2. Proliferation of oligodendrocyte precursors in neuronal cocultures. In cultures grown for $1 \mathrm{~d}$ and then given BrdU for an additional $24 \mathrm{hr}$ before immunolabeling, two daughter precursor cells are shown by phase contrast $(A)$ and anti-GD3 labeling $(B)$ to have incorporated BrdU into their nuclei $(C)$. Magnification, $400 \times$.
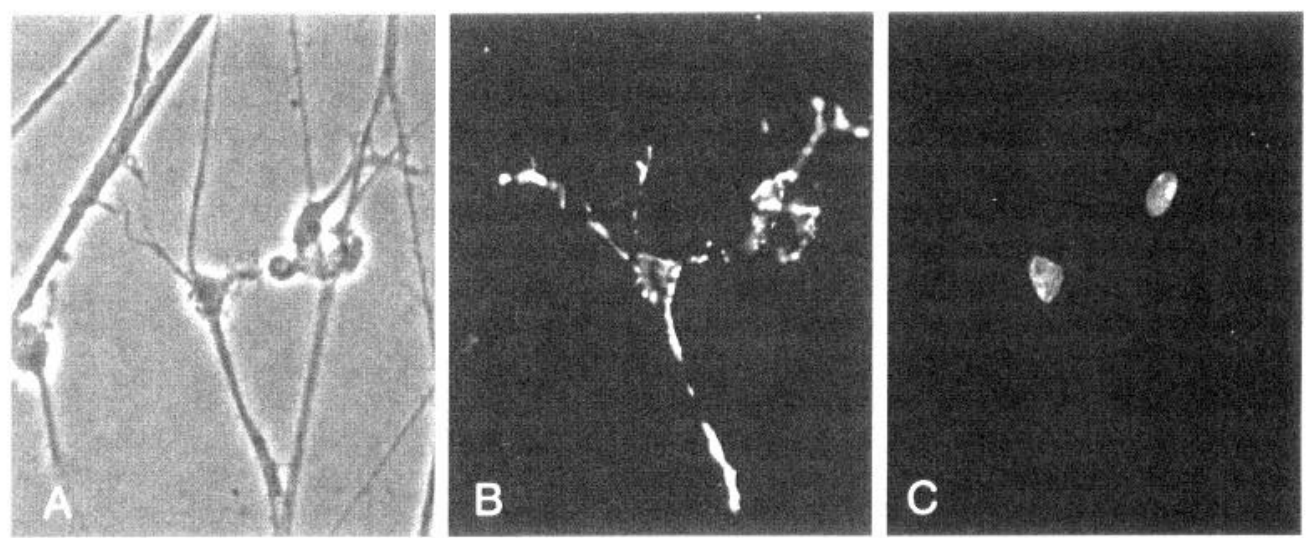

Feltri et al., 1994; Niessen et al., 1994a). To determine whether this switch is also seen in oligodendrocytes, we performed $\beta 4$ immunoprecipitations on oligodendrocytes grown in isolation and in the presence of rat DRG neurons. These experiments were performed using the 346-11A monoclonal antibody, which recognizes mouse but not rat $\beta 4$ integrins. In control experiments in which mouse Schwann cells were grown for $10 \mathrm{~d}$ in the presence of rat DRG neurons, the Schwann cells express two bands of the expected molecular weights for $\alpha 6(130 \mathrm{kDa})$ and $\beta 4(210 \mathrm{kDa})$, whereas rat DRG neurons alone show no bands (Fig. 10). This confirms that the $\alpha 6 \beta 4$ integrin is expressed by the mouse Schwann cells in our culture system. Identical immunoprecipitations on oligodendrocytes, either in isolation or in established neuronal cocultures, failed to show any bands (Fig. 10), demonstrating that oligodendrocytes, unlike Schwann cells, did not express the $\alpha 6 \beta 4$ integrin in these cultures.

\section{$\alpha v$ Integrins}

We found previously that isolated oligodendroglia express several members of the $\alpha$ v family of integrins and show developmental regulation, with a switch during differentiation from $\alpha v \beta 1$ to $\alpha v \beta 5$ (Milner and ffrench-Constant, 1994). This raises the question as to whether $\alpha v \beta 5$ is seen when oligodendrocyte differentiation occurs

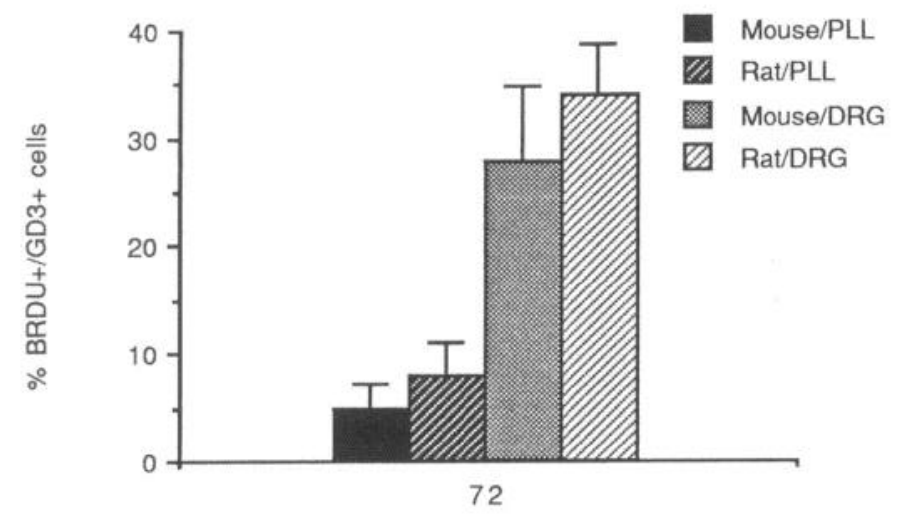

Hours in culture

Figure 3. Oligodendrocyte precursors from mouse and rat were cultured for $2 \mathrm{~d}$ in the presence and absence of rat neurons (DRG and PLL, respectively) and then given a $24 \mathrm{hr}$ pulse of $\mathrm{BrdU}$. Cultures were then double-stained for the oligodendrocyte precursor marker GD3 and BrdU. Note that the proportion of oligodendrocyte precursor cells incorporating $\mathrm{BrdU}$ into their nuclei was greatly increased in both species when cultured with neurons. Black bar indicates mouse/PLL; bar with thick diagonal lines indicates rat/PLL; shaded bar indicates mouse/DRG; and bar with thin diagonal lines indicates rat/DRG. in the presence of neurons. Because of the lack of mouse-specific anti- $\alpha v$ antibodies, an alternative approach was taken to analyze $\beta 5$ integrins on oligodendrocytes in the xenotypic coculture system. This approach involves three sets of experiments. First, $\alpha \mathrm{v}$ immunoprecipitations were performed on rat DRG neurons alone to establish the pattern of $\alpha \mathrm{v}$ expression without the presence of glial cells. DRG neurons expressed one $\alpha v$ integrin, consisting of the $\alpha$ v subunit running at $140 \mathrm{kDa}$, and one associated $\beta$ subunit running at $80 \mathrm{kDa}$ (Fig. 11). This $\beta$ subunit comigrated with the major $\beta$ subunit expressed by oligodendroglia; we have shown previously that this band comprises $\beta 3$ integrin, at least in part, and is quite distinct from $\beta 5$ and $\beta 1$. No other $\alpha v$-associated $\beta$ subunits were expressed by rat DRG neurons, showing that $\beta 5$ is not expressed on DRG neurons grown in isolation. Next, $\alpha v$ immunoprecipitations were performed on established xenotypic cocultures. In these experiments, only one additional band was observed running at $90 \mathrm{kDa}$ and comigrating with a band already identified as the $\beta 5$ subunit in isolated oligodendrocyte cultures (Fig. 11). No band was seen at the size expected for oligodendroglial $\beta 1$ (Fig. 11). This suggests that differentiated oligodendrocytes express $\beta 5$ but not $\beta 1$ in the presence of neurons, just as they do in isolation. Because the anti- $\alpha v$ antisera recognize $\alpha v$ integrins on both cell types, however, it was necessary to exclude the possibility that DRG neurons were

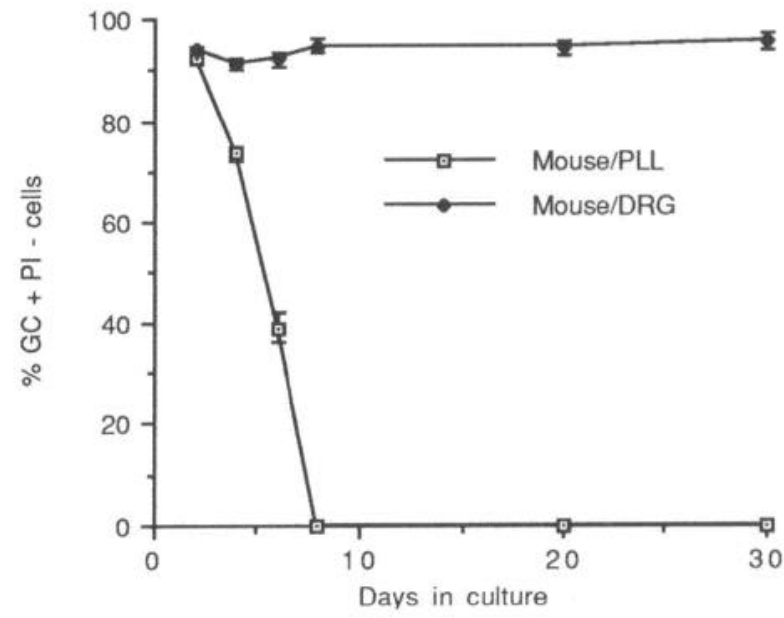

Figure 4. Neurons stimulate oligodendroglial cell survival. Mouse oligodendrocyte survival was assessed by staining cocultures with anti-GalC monoclonal antibody and propidium iodide. The proportion of $\mathrm{GalC}^{+}$ cells that excluded propidium iodide was increased by the presence of neurons, showing that rat DRG neurons promote mouse oligodendrocyte survival. Open squares with center dots indicate mouse/PLL, and filled diamonds indicate mouse/DRG. 

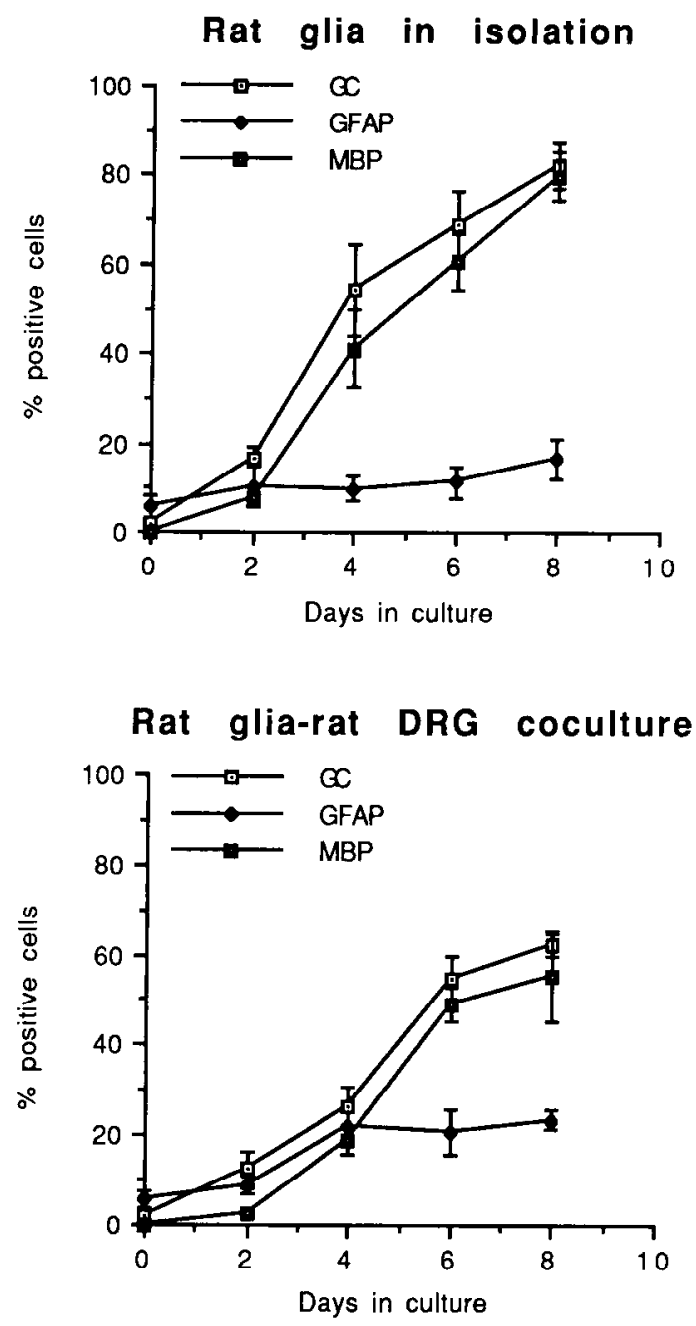
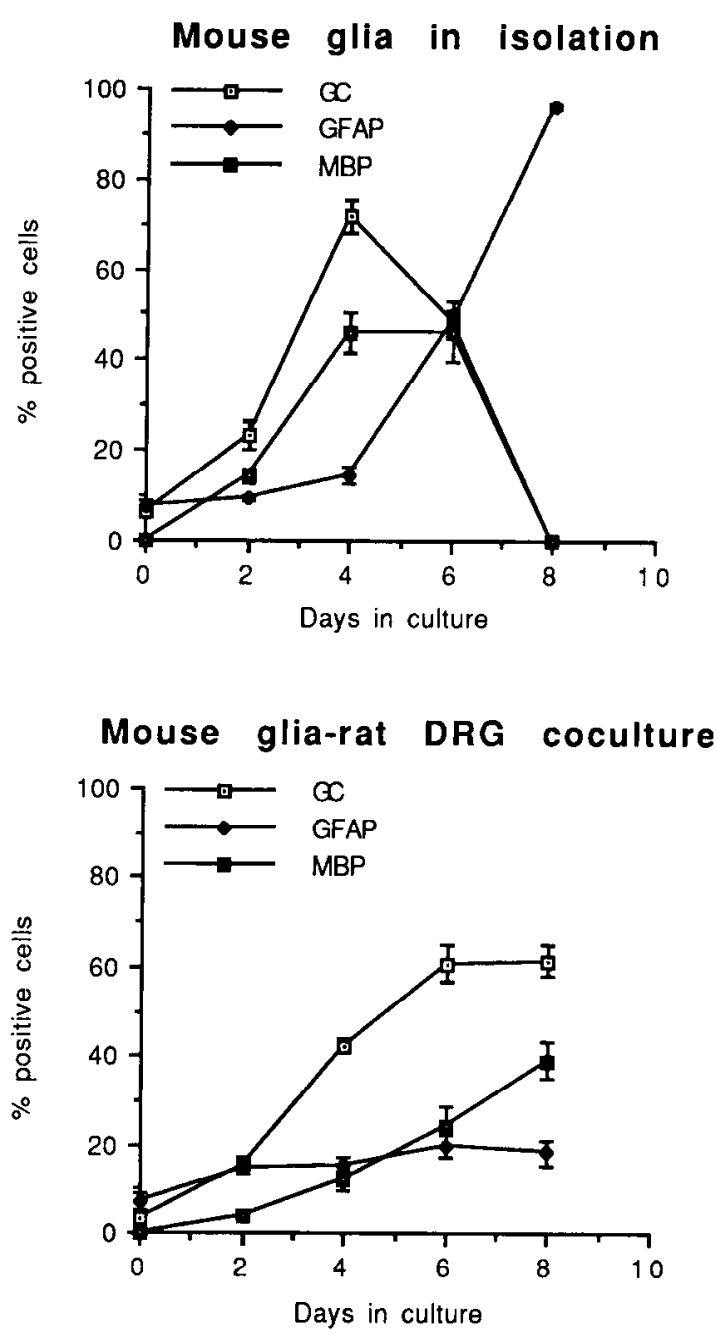

Figure 5. Differentiation of oligodendroglial cells in neuronal cocultures. Oligodendrocyte precursors derived from mouse and rat were grown in the absence (top) or presence (bottom) of rat DRG neurons, and the number of $\mathrm{GalC}^{+}$(open squares with center dots), $\mathrm{MBP}^{+}$(filled diamonds), or GFAP (jilled squares with white dots) cells was expressed as a percentage of the total cell number. A majority of all cells in the two conditions differentiated into oligodendrocytes expressing GalC and MBP, whereas a minority differentiated into astrocytes expressing GFAP. Note that coculture with ncurons delayed oligodendrocyte differentiation in both species by 3-4 d. The increase in the percentage of cells with an astrocytic phenotype in mouse glia grown in isolation reflects reduced survival of mouse oligodendroglia grown under these conditions.

induced to express $\alpha v \beta 5$ on contact with oligodendrocytes. We immunoprecipitated established cocultures with the mouse monoclonal antibody $\mathrm{P} 3 \mathrm{G} 2$, which recognizes rat but not mouse $\alpha \mathrm{v} \beta 5$, thereby specifically examining the DRG neuron contribution to the $\beta 5$ band. This immunoprecipitation showed no bands (Fig. 11), indicating that oligodendrocytes grown in coculture with neurons express $\alpha v \beta 5$ and $\alpha v \beta 80 \mathrm{kDa}$ but not $\alpha v \beta 1$, the same pattern of $\alpha \mathrm{v}$ integrins as differentiated oligodendrocytes grown in isolation. Some variability in the relative level of $\beta 5$ expression with respect to $\alpha v$ was seen in our coculture experiments (compare Fig. 11A, lane 3 with $B$, lane 1), which we believe represents the differing ratios of oligodendroglia to neurons in our cultures.

\section{DISCUSSION}

In vitro cocultures of dissociated neurons and glia have become an established means of examining axo-glial interactions that lead to oligodendrocyte and Schwann cell differentiation and myelination (Kleitman et al., 1991). In vivo, the axonal processes of DRG sensory neurons are myelinated within the CNS by oligodendrocytes and within the peripheral nervous system (PNS) by Schwann cells
(Brodal, 1992). DRG neurons support myelination by both cell types in vitro (Wood and Williams, 1984; Wood and Bunge, 1986b; Eldridge et al., 1987, 1989). Cross-species myelination has been demonstrated previously, both in vivo by transplanting mouse oligodendrocytes into demyelinated rat spinal cords (Crang and Blakemore, 1991) and rat Schwann cells into the mouse spinal cord (Duncan et al., 1981), and in vitro by myelin formation within mouse cerebellar slices by rat oligodendrocytes (Nishimura et al., 1985). We have developed a modification of the in vitro system of myelination by using mouse oligodendrocytes and Schwann cells in coculture with rat DRG ncurons and have illustrated its validity as a tool to study axo-glial interactions by demonstrating the effect of axons on mouse oligodendrocyte proliferation, survival, and differentiation.

Proliferation of both neonatal and adult rat oligodendroglial cells has been described in coculture with DRG neurons (Wood and Williams, 1984; Wood and Bunge, 1986a; Zajicek and Compston, 1994). This response is attributable to axonal membrane-bound and -soluble factors secreted by the neurons themselves (Chen and De Vries, 1989; Hardy and Reynolds, 1993). Our results show that 
Figure 6. Preferential adhesion of oligodendroglial cells to axons. After $4 \mathrm{hr}$ of coculture, mouse oligodendrocyte precursors had adhered preferentially to rat axons as seen by phase contrast $(A)$ and by staining with the A2B5 monoclonal antibody $(B)$. Note that both precursors and axons are detected by the antibody A2B5 and that the precursor cells (which have not had sufficient time in culture to extend the length of processes seen here) are all adjacent to the axons. After $3 \mathrm{~d}$ in culture, $\mathrm{GalC}^{+}$oligodendrocytes are still adherent to the axons, as shown by phase contrast $(C)$ and antiGalC staining $(D)$. Note that the lower magnification in $C$ and $D$ shows clusters of oligodendrocytes that are localized to the axonal branch points in these cultures. Magnification: $A, B$, $300 \times ; C, D, 128 \times$.

Figure 7. Response of mouse oligodendroglia to axonal adhesion. Oligodendrocyte processes align along axons, as shown after $6 \mathrm{~d}$ by phase contrast $(A)$ and anti-GalC labeling $(B)$, and after $8 \mathrm{~d}$ by phase contrast $(C)$ and by anti-MBP labeling $(D)$. Note that oligodendrocyte processes coalign with the axons (seen by phase in $A$ and $C$ ) and that one single oligodendrocyte (as shown in $D$ ) interacts with multiple axons, causing an array of processes at different angles to one another. Magnification: $A, B, 128 \times ; C, D, 300 \times$.

Figure 8. Myelin formation in xenoculture visualized by electron microscopy. After 4 weeks in coculture, some mouse oligodendrocytes had wrapped rat DRG axons in concentric myelin membrane $(A)$, which appeared compacted (inset). Double wrapping of an axon was also found $(B)$, with two sets of inner and outer compacted myelin loops present (inset).

mouse oligodendroglia respond to rat DRG neurons with an identical proliferative response. We also observed increased survival of oligodendroglial cells, with the rat DRG neurons preventing programmed cell death of a majority of mouse oligodendroglial cells. A survival-promoting effect of neurons has been described both in vivo and in vitro (Barres et al., 1993), and our results show that just like
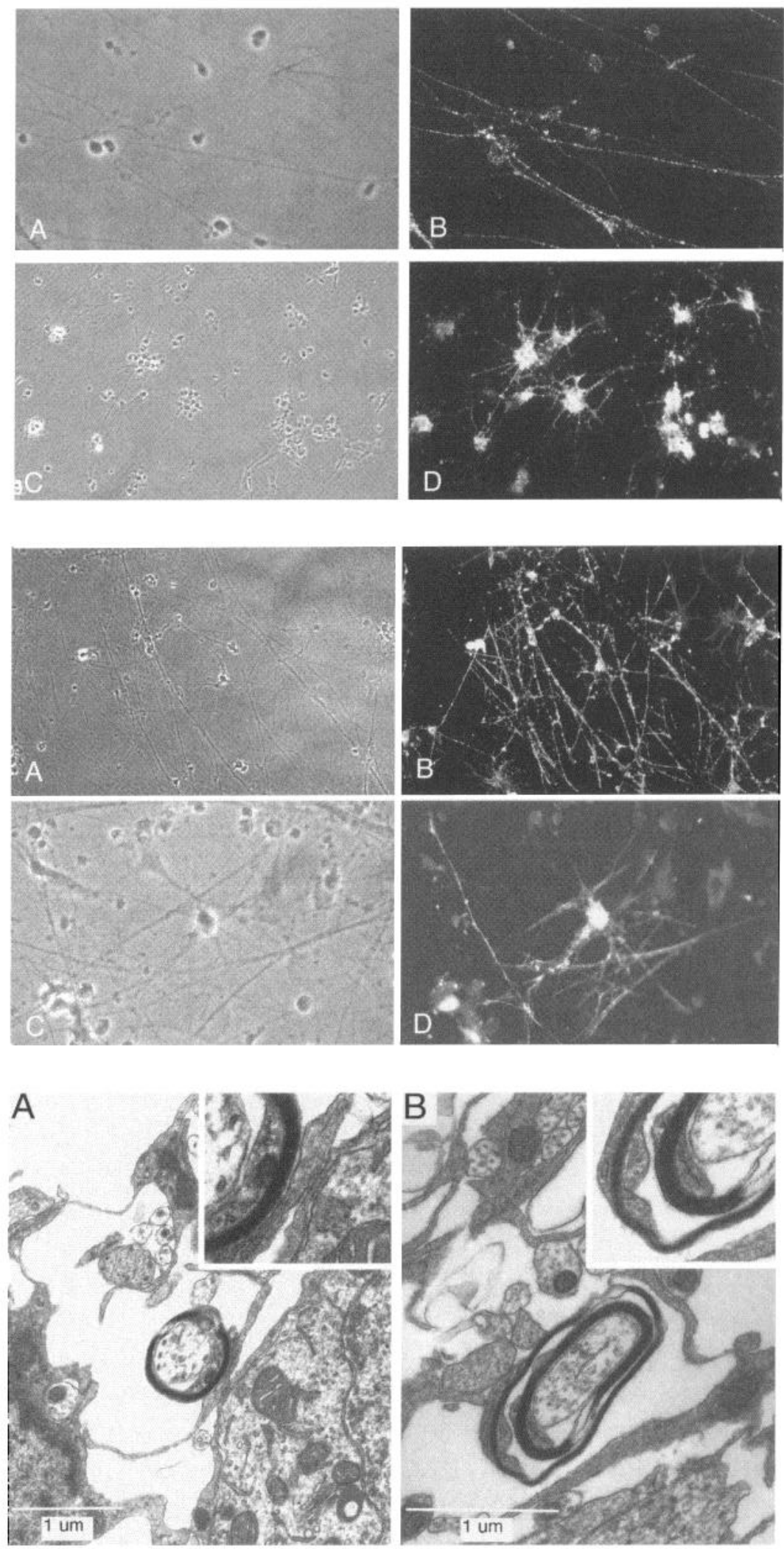

the mitogenic stimuli, these rat-derived survival signals are recognized by mouse oligodendroglia.

We also observed two significant effects on oligodendrocyte differentiation in the xenotypic cultures. First, the initial differentiation of oligodendrocyte precursors was delayed. Oligodendrocyte precursors differentiate at a time determined by an intrinsic 


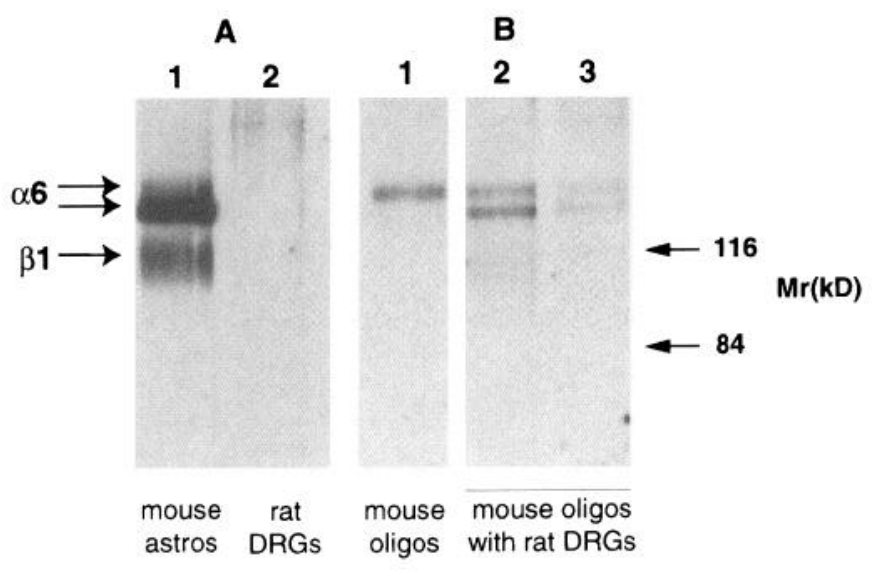

Figure 9. $\alpha 6$ expression on mouse oligodendroglia in neuronal coculture. Two separate parts of a single gel are shown in $A$ and $B$, both immunoprecipitations of biotin-labeled cell culture lysates using the $\mathrm{GoH} 3$ monoclonal antibody and run out on a nonreducing gel. $A$, Mouse astrocytes and rat DRG (lanes 1 and 2, respectively). Note that $\mathrm{GoH} 3$ recognizes only mouse $\alpha 6$ and immunoprecipitates no bands from the rat DRG lysate. $B$, Mouse oligodendrocytes grown in the absence (lane 1) or presence (lanes 2 and 3, showing two different cocultures) of rat DRG neurons. Note that two forms of $\alpha 6$ are expressed on oligodendrocytes, with a shift to the lower form seen in the cocultures.

clock mechanism, which seems to count the cell divisions driven by mitogenic growth factors (Temple and Raff, 1986; Barres and Raff, 1994). In their absence, the cells drop out of division and differentiate prematurely into oligodendrocytes (Temple and Raff, 1985). Our results showing delayed differentiation, therefore, are explained most simply by the neuronally produced mitogen driving the normal differentiation timing mechanism. Second, later stages of oligodendrocyte differentiation are enhanced by coculture with neurons. There was extensive membrane sheet formation in culture (C. Shaw, unpublished observations) and,

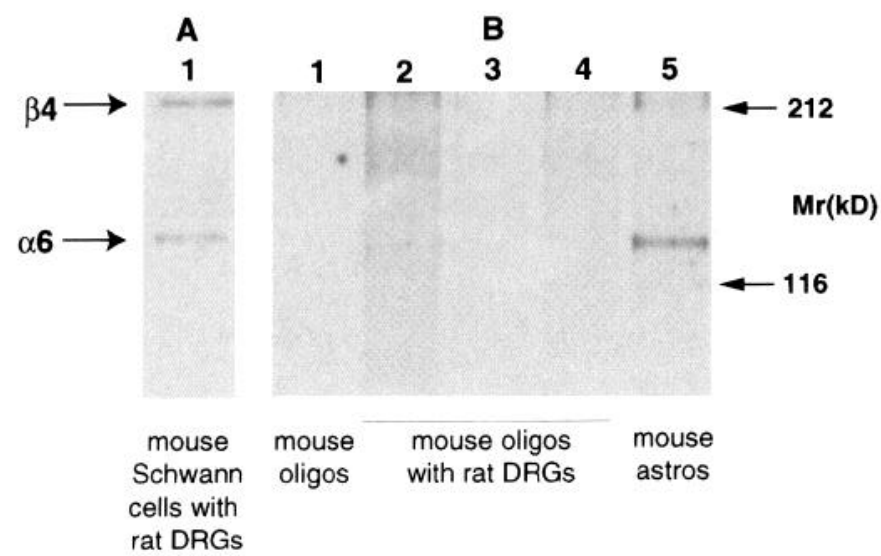

Figure 10. Expression of $\beta 4$ in association with $\alpha 6$ on Schwann cells and not oligodendrocytes. Two separate experiments are shown in $A$ and $B$, both immunoprecipitations of biotin-labeled cell culture lysates using the $346-11 \mathrm{~A}$ monoclonal antibody and run out on nonreducing gels. $A$, Schwann cells express $\alpha 6 \beta 4$ when grown in coculture with rat DRG neurons. Note that the 346-11A antibody coprecipitates $\alpha 6$. $B$, Mouse oligodendrocytes grown in the absence (lane 1 ) or presence (lanes 2-4, showing three different cocultures) of rat DRG neurons. Note that $\alpha 6$ is not precipitated by the $346-11 \mathrm{~A}$ antibody in oligodendrocytes. The adjacent lane (lane 5) shows a positive control in which lysates from astrocytes have been immunoprecipitated under identical conditions. Note that $\alpha 6$ is precipitated by the anti- $\beta 4$ antibody on these cells. more important, the production of compact myelin sheaths as demonstrated previously by Wood and colleagues (Wood and Williams, 1984; Wood and Bunge, 1986b). Our results confirm that the cell-cell signals required for initiating and forming the myelin sheath can be recognized across species in vitro, and this is consistent with the results obtained in vivo (Duncan et al., 1981; Crang and Blakemore, 1991). Because myelin sheaths were rare in our cultures, however, it seems likely that not all of the required signals for extensive oligodendroglial myelin formation are present.

\section{Integrin expression on oligodendrocytes in contact with neurons}

A major aim of this study was to determine the difference, if any, between integrin expression on oligodendrocytes grown with and without neurons. We found previously that two classes of integrins, $\alpha 6$ and $\alpha v$, are expressed on purified oligodendroglia (Milner and ffrench-Constant, 1994). $\alpha 6$ was seen in association with $\beta 1$, whereas $\alpha$ v was expressed in association with three different $\beta$ subunits-with a $\beta$ subunit at $80 \mathrm{kDa}$ expressed at all stages of differentiation and with $\beta 1$ in oligodendrocyte precursors and $\beta 5$ in differentiated oligodendrocytes. We could not examine $\alpha v \beta 1$ specifically in our xenocultures because of the lack of speciesspecific reagents. Our results are consistent with the switch in $\alpha \mathrm{v}$ integrins seen in the purified cultures, however, because $\alpha v \beta 5$ but not $\alpha v \beta 1$ was observed on oligodendrocytes in established cocultures. These observations suggest that the upregulation of $\alpha v \beta 5$ associated with oligodendrocyte differentiation does not require axonal contact. Just as with the expression of myelin-specific genes (Zeller et al., 1985; Dubois-Dalcq et al., 1986), oligodendrocytes differentiating in purified cultures seem to go through developmental changes in integrin expression, despite the absence of neurons.

Schwann cells resemble oligodendrocytes in their expression of $\alpha 6 \beta 1$ before myelination. The onset of myelination in Schwann cells is associated with a switch from $\alpha 6 \beta 1$ to $\alpha 6 \beta 4$, with the upregulation of $\beta 4$ being dependent on axonal contact (Einheber et al., 1993; Feltri et al., 1994; Niessen et al., 1994a). This raises the obvious question as to whether oligodendrocytes also upregulate $\beta 4$ in association with axo-glial contact before and during myelination. A previous study using immunoperoxidase staining of tissue sections failed to find any evidence for $\beta 4$ expression in the CNS, suggesting that $\alpha 6 \beta 4$ was not expressed in myelinating oligodendrocytes (Sonnenberg et al., 1990). We have addressed this directly by using a mouse-specific anti-integrin $\beta 4$ antibody, and we show that oligodendrocytes differ from Schwann cells in that they do not upregulate $\beta 4$, and $\beta 1$ remains the partner of $\alpha 6$ even in the presence of myelin sheath formation. We believe an alternative explanation that the final stages of myelin sheath formation are so rare in our cultures that any switch from $\alpha 6 \beta 1$ to $\alpha 6 \beta 4$ would not be seen to be unlikley. In an immunofluorescence study of myelinating rat DRG-rat Schwann cell cocultures, Einheber at el. (1993) found $\beta 4$ to be upregulated in association with ensheathment but before compaction. Moreover, in an immunoprecipitation protocol similar to our own, Fernandez-Valle et al. (1994) found small amounts of $\alpha 6 \beta 4$ in Schwann cells in such cultures even before myelination. Given the evidence for extensive axo-glial interaction in our cultures, some $\beta 4$ expression by oligodendrocytes, therefore, would be expected if they behaved like Schwann cells in switching from $\alpha 6 \beta 1$ to $\alpha 6 \beta 4$. The absence of $\beta 4$ expression in our experiments, as determined by a sensitive technique such as immunoprecipitation, argues in favor of a 
Figure 11. $\quad 35$ expression in mouse oligodendrocyte-rat DRG neuron cocultures. Two sets of experiments are shown. In $A$, rat DRG neurons have been grown without (lane 2) or with (lane 3) mouse oligodendrocytes, and then biotin-labeled cell lysates have been immunoprecipitated with anti- $\alpha v$ antisera. Note that $\alpha v \beta 80 k D$ is seen in both sets of cultures, whereas $\beta 5$ is expressed only in the cocultures, suggesting that this subunit is expressed on oligodendroglia. A lysate prepared from mouse oligodendrocyte precursors grown in the absence of neurons and then immunoprecipitated with anti- $\alpha v$ antisera is shown next to this experiment (lane 1 ) to indicate the position of $\beta 1$. Note that $\beta 1$ is not expressed on oligodendroglia grown in coculture (lane 3 ). $B$ confirms the conclusion that $\beta 5$ is expressed on oligodendroglia by showing a biotin-labeled rat DRG-mouse oligodendrocyte coculture lysate immunoprecipitated either with the anti- $\alpha v$ antisera (lane 1) or the P3G2 monoclonal antibody (lane 2), which recognizes rat but not mouse $\alpha \vee \beta 5$. Note that P3G2 does not precipitate $\beta 5$ from the DRG neurons, confirming the oligodendroglial origin of this subunit. Lane 3 shows a positive control for the P3G2 antibody in which biotin-labeled lysates from rat astrocytes were immunoprecipitated with this antibody. Note that $\alpha \vee \beta 5$ is precipitated from these cells.
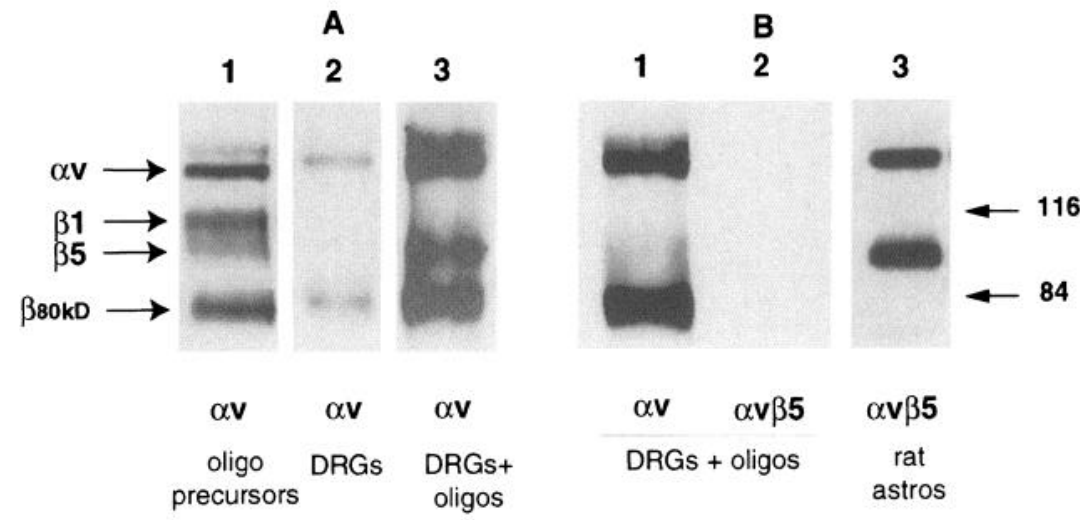

$\operatorname{Mr}(k D)$

fundamental difference between oligodendrocytes and Schwann cells in this regard.

The lack of $\beta 4$ expression on oligodendrocytes raises an obvious question concerning the role of $\beta 4$ in Schwann cells. Schwann cells, unlike oligodendrocytes, secrete a basal lamina around the nonaxonal surface during myelination (Bunge et al., 1986). This is required for myelin sheath formation; culture conditions that prevent basal lamina formation by lacking the ascorbic acid necessary for collagen assembly do not allow myelination (Eldridge et al., 1987, 1989). Others have shown that $\alpha 6 \beta 4$ binds laminin (Lee et al., 1992; Niessen et al., 1994b; Spinardi et al., 1995), an ECM component of this basal lamina, and that $\alpha 6 \beta 4$ is concentrated in the hemidesmosomes that are responsible in some cell types for adhesion to the basal lamina (Carter et al., 1990; Stepp et al., $1990)$. Taken together, these observations suggest that $\alpha 6 \beta 4$ is the integrin responsible for adhesion of the Schwann cell to laminin in the basal lamina. This interaction would be expected to anchor the Schwann cell to the overlying basal lamina, thereby facilitating myelination by preventing counter-rotation of the Schwann cell body around the axon during wrapping. Oligodendrocytes, unlike Schwann cells, myelinate more than one axon, and the multiple processes radiating from the cell will effectively stabilize the cell body during myelin sheath formation. As a result, local anchorage of the cell by basal lamina is not necessary, and $\beta 4$ expression on oligodendrocytes, therefore, would not be required.

In addition to any role in anchorage, $\beta 4$ expression in differentiated Schwann cells might also contribute to differences in behavior between oligodendrocytes and Schwann cells. The cytoplasmic domain of $\beta 4$ shares no homology with the cytoplasmic domain of other $\beta$ subunits and is $>1000$ amino acids in size as compared with 47 amino acids for the $\beta 1$ cytoplasmic domain (Hogervorst et al., 1990; Suzuki and Naitoh, 1990; Tamura et al., $1990)$. The $\beta 4$ cytoplasmic domain may have a role in cell signaling, as has been shown for other integrin cytoplasmic domains (Chan et al., 1992; Hynes, 1992; Pasqualini and Hemler, 1994). If so, it will be important to determine whether the expression of $\beta 4$ plays a role in the ability of Schwann cells to de-differentiate and proliferate after peripheral nerve lesions (Griffin and Hoffman, 1993). This property is in contrast to the lack of proliferative response seen in CNS oligodendrocytes after demyelinating lesions (Godfraind et al., 1989; Reynolds and Wilkin, 1993) and may represent one important reason why PNS lesions remyelinate more effectively than those of the CNS.

In conclusion, we have established a xenotypic culture system in which CNS oligodendrocytes form appropriate contacts with neurons. As we have shown, these cultures can be used to analyze the expression of cell-surface molecules in either neuronal or glial populations by using species-specific antibodies. They also offer a promising approach toward investigating the function of integrins and other cell-surface molecules in myelination by allowing the use of species-specific antibodies to block glial molecules without perturbing the function of the neurons.

\section{REFERENCES}

Adams JC, Watt FM (1993) Regulation of development and differentiation by the extracellular matrix. Development 117:1183-1198.

Armstrong RC, Harvath L, Dubois-Dalcq ME (1990) Type 1 astrocytes and oligodendrocyte-type 2 astrocyte glial progenitors migrate toward distinct molecules. J Neurosci Res 27:400-407.

Barres BA, Raff MC (1994) Control of oligodendrocyte number in the developing rat optic nerve. Neuron 12:935-942.

Barres BA, Hart IK, Coles HSR, Burne JF, Voyvodic JT, Richardson WD, Raff MC (1992) Cell death and control of cell survival in the oligodendrocyte lineage. Cell 70:31-46.

Barres BA, Jacobson MD, Schmid R, Sendtner M, Raff MC (1993) Does oligodendrocyte survival depend on axons? Curr Biol 3:489-497.

Bartsch S, Bartsch U, Dorries U, Faissner A, Weller A, Ekblom P, Schachner M (1992a) Expression of tenascin in the developing and adult cerebellar cortex. J Neurosci 12:736-749.

Bartsch U, Bartsch S, Dörries U, Schacher M (1992b) Immunohistological localization of tenascin in the developing and lesioned adult mouse optic nerve. Eur J Neurosci 4:338-352.

Behar T, McMorris FA, Novotny EA, Barker JL, DuboisDalcq M (1988) Growth and differentiation properties of $\mathrm{O}-2 \mathrm{~A}$ progenitors purified from rat cerebral hemispheres. J Neurosci Res 21:168-180.

Brockes J, Fields K, Raff M (1979) Studies on cultured rat Schwann cells. I. Establishment of purified populations from cultures of peripheral nerve. Brain Res 165:105-118. 
Brodal P (1992) The central nervous system: structure and function. New York: Oxford UP.

Bunge RP, Bunge MB, Eldridge CF (1986) Linkage between axonal ensheathment and basal lamina production by Schwann cells. Anmu Rev Neurosci 9:305-328.

Cardwell MC, Rome LH (1988) RGD-containing peptides inhibit the synthesis of myelin-like membrane by cultured oligodendrocytes. J Cell Biol 107:1551-1559.

Carter WG, Kaur P, Gil SG, Gahr PJ, Wayner EA (1990) Distinct functions for integrins $\alpha 3 \beta 1$ in focal adhesions and $\alpha 6 \beta 4 / B u l l o u s$ pemphigoid antigen in a new stable anchoring contact (SAC) of keratinocytes: relation to hemidesmosomes. J Cell Biol 111:3141-3154.

Chan BMC, Kassner PD, Schiro JA, Byers HR, Kupper TS, Hemler ME (1992) Distinct cellular functions mediated by different VLA integrin $\alpha$ subunit cytoplasmic domains. Cell 68:1051-1060.

Chen S-J, De Vries G (1989) The mitogenic effect of the axolemmaenriched fraction on cultured oligodendrocytes. J Neurochem $52: 325-327$.

Chun JJM, Shatz CJ (1988) A fibronectin-like molecule is present in the developing cat cerebral cortex and is correlated with subplate neurons. J Cell Biol 106:857-872.

Crang A, Blakemore W (1991) Remyelination of demyelinated rat axons by transplanted mouse oligodendrocytes. Glia 4:305 313 .

Curtis RAJ, Cohen J, Fok-Seang J, Hanley MR, Gregson NA, Reynolds R, Wilkin GP (1988) Development of rat macroglial cells in rat cerebellum. I. Use of antibodies to follow early in vivo development and migration of oligodendrocytes. J Neurocytol 17:43-54.

DeSimone DW (1994) Adhesion and matrix in vertebrate development. Curr Opin Cell Biol 6:747-751.

Dubois-Dalcq M, Behar T, Hudson L, Lazzarini RA (1986) Emergence of three myelin proteins in oligodendrocytes cultured without neurons. J Ccll Biol 102:384-392.

Duncan I, Aguayo A, Bunge R, Wood P (1981) Transplantation of rat Schwann cells grown in tissue culture into the mouse spinal cord. J Neurol Sci 49:241-252.

Einheber S, Milner TA, Giancotti F, Salzer JL (1993) Axonal regulation of Schwann cell integrin expression suggests a role for $\alpha 6 \beta 4$ in myelination. J Cell Biol 123:1223-1236.

Eldridge CF, Bunge MB, Bunge RP (1989) Differentiation of axonrelated Schwann cells in vitro. II. Control of myelin formation by basal lamina. J Neurosci 9:625-638.

Fldridge CF, Bunge MB, Runge RP, Wood PM (1987) Differentiation of axon-related Schwann cells in vitro. I. Ascorbic acid regulates basal lamina assembly and myelin formation. J Cell Biol 105:1023-1034.

Feltri ML, Scherer SS, Nemni R, Kamholz J, Vogelbacker H, Scott MO, Canal N, Quaranta V, Wrabetz L (1994) $\beta 4$ integrin expression in myelinating Schwann cells is polarized, developmentally regulated and axonally dependent. Development 120:1287-1301.

Fernanadez-Valle C, Gwynn L, Wood PM, Carbonetto S, Bunge MB (1994) Anti- $\beta 1$ integrin antibody inhibits Schwann cell myelination. J Neurobiol 25:1207-1226.

Godfraind C, Friedrich VL, Holmes KV, Dubois-Dalcq M (1989) In vivo analysis of glial cell phenotypes during a viral demyelinating disease in mice. J Cell Biol 109:2405-2416.

Griffin JW, Hoffman PN (1993) Degeneration and regeneration in the peripheral nervous system. In: Peripheral neuropathy, 3rd Ed, pp $361-$ 376. Philadelphia: Saunders.

Hardy R, Reynolds R (1991) Proliferation and differentiation potential of rat forcbrain oligodendroglial progenitors both in vitro and in vivo. Development 111:1061-1080.

Hardy R, Reynolds R (1993) Rat cerebral cortical neurons in primary culture release a mitogen specific for early $\left(\mathrm{GD}^{+} / \mathrm{O}^{-}\right)$oligodendroglial progenitors. J Neurosci Res 34:589-600.

Hogervorst F, Admiraal LG, Niessen C, Kuikman I, Janssen H, Daams H, Sonnenberg A (1993) Biochemical characterization and tissue distribution of the $\mathrm{A}$ and $\mathrm{B}$ variants of the integrin $\alpha 6$ subunit. $\mathrm{J}$ Cell Biol 121:179-191.

Hogervorst F, Kuikman I, Borne A, Sonnenberg A (1990) Cloning and sequence analysis of beta-4 cDNA: an integrin subunit that contains a unique $118 \mathrm{kd}$ cytoplasmic domain. EMBO J 9:756-770.

Hynes RO (1992) Integrins: versatility, modulation and signaling in cell adhesion. Cell 69:11-25.

Hynes RO (1994) Genetic analyses of cell-matrix interactions in development. Curr Opin Genet Dev 4:569-574.
Kennel SJ, Foute LJ, Falcioni R, Sonnenberg A, Stringer CD, Crouse C, Hemler ME (1989) Analysis of the tumour associated antigen TSP180: identity with $\alpha 6 \beta 4$ in the integrin superfamily. J Biol Chem 264:15515-15521.

Kleitman N, Wood P, Bunge R (1991) Tissue culture methods for the study of myelination. In: Culturing nerve cells, pp 337-377. Cambridge: MIT.

Lee EC, Lotz MM, Steele GD, Mercurio AM (1992) The integrin $\alpha 6 \beta 4$ is a laminin receptor. J Cell Biol 117:671-678.

Levi G, Aloisi F, Wilkin GP (1987) Differentiation of cerebellar bipotential glial precursors into oligodendrocytes in primary culture: developmental profile of surface antigens and mitotic activity. J Neurosci Res 18:407-417.

Levison SW, McCarthy KD (1991) Characterization and partial purification of AIM: a plasma protein that induces rat cerebral type-2 astroglia from bipotential glial progenitors. Neurochemistry 57:782-794.

Louis J-C, Magal E, Takayama S, Varon S (1993) CNTF protection of oligodendrocytes against natural and tumor necrosis factor induced death. Science 259:689-692.

Malek-Hedayat S, Rome I.H (1994) Fxpression of a $\beta 1$-related integrin by oligodendroglia in primary culture: evidence for a functional role in myelination. J Cell Biol 124:1039-1046.

McCarthy KD, De Vellis J (1980) Preparation of scparate astroglial and oligodendroglia cell cultures from rat cerebral tissue. J Cell Biol 85:890-902.

Mckinnon RD, Piras G, Ida JA, Dubois-Dalcq M (1993) A role for TGF- $\beta$ in oligodendrocyte differentiation. J Cell Biol 121:1397-1407.

McLoon SC, McLoon LK, Palm SL, Furcht LT (1988) Transient expression of laminin in the optic nerve of the developing rat. $J$ Neurosei 8:1981-1990.

Milner R, ffrench-Constant C (1994) A developmental analysis of oligodendroglial integrins in primary cells: changes in $\alpha$ v-associated $\beta$ subunits during differentiation. Development 120:3497-3506.

Neugebauer KM, Emmett CJ, Venstrom KA, Reichardt LF (1991) Vitronectin and thrombospondin promote retinal neuritc outgrowth: developmental regulation and role of integrins. Neuron 6:345-358.

Niessen CM, Cremona O, Daams H, Ferraresi S, Sonnenberg A, Marchisio PC (1994a) Expression of the integrin $\alpha 6 \beta 4$ in peripheral nerves: localization in Schwann and perineural cells and different variants of the $\beta 4$ subunit. J Cell Sci 107:543-552.

Niessen CM, Hogervorst F, Jaspars LH, DeMelker AA, Delwel GO. Hulsman EHM, Kuikman I, Sonnerberg A (1994b) The $\alpha 6 \beta 4$ integrin is a receptor for both laminin and kalinin. Exp Cell Res 2111:360-367.

Nishimura R, Blank N, Tiekotter K, Cole R, De Vellis J (1985) Myelination of mouse cerebellar explants by rat cultured oligodendrocytes. $J$ Neurosci 5:1-10.

Noble M, Murray K, Stroobant P, Waterficld MD, Riddle P (1988) Platelet-derived growth factor promotes division and motility and inhibits premature differentiation of the oligodendrocyte/type-2 astrocyte progenitor cell. Nature 333:560-562.

O'Shea KS, Rheinheimer JST, Dixit VM (1990) Deposition and role of thrombospondin in the histogenesis of the cerebellar cortex. J Cell Biol 110:1275-1283.

Pasqualini R, Hemler ME (1994) Contrasting roles for integrin $\beta 1$ and $\beta 5$ cytoplasmic domains in subcellular localization, cell proliferation and cell migration. J Cell Biol 125:447-460.

Pfeiffer SE, Warrington AE, Bansal R (1993) The oligodendrocyte and its many cellular processes. Trends Cell Biol 3:191-197.

Raff MC, Miller RH, Noble M (1983) A glial progenitor cell that develops in vitro into an astrocyte or an oligodendrocyte depending on culture medium. Nature 303:390-396.

Ranscht B, Clapshaw PA, Price J, Noble M, Seifert W (1982) Development of oligodendrocytes and Schwann cells studied with a monoclonal antibody against galactocerebroside. Proc Natl Acad Sci USA 79:2709-2713.

Reynolds R, Wilkin GP (1993) Cellular reaction to an acute demyelinating/remyelinating lesion of the rat brainstem-localization of GL3 ganglioside immunoreactivity. J Neurosci Res 36:417-434.

Sonnenberg A, Janssen H, Hogervorst F, Calafat J, Hilgers J (1987) A complex of platelet glycoproteins Ic and Ila identified by a rat monoclonal antibody. J Biol Chem 262:10376-10383.

Sonnenberg A, I inders C, Daams J, Kennel S (1990) The $\alpha 6 \beta 1$ (VLA- 6 ) and $\alpha 6 \beta 4$ protein complexes: tissue distribution and biochemical properties. J Cell Sci 96:207-217. 
Spinardi L, Einheber S, Cullen T, Milner TA, Giancotti FG (1995) A recombinant tail-less integrin $\beta 4$ subunit disrupts hemidesmosomes, but does not suppress $\alpha 6 \beta 4$-mediated cell adhesion to laminins. J Cell Biol 129:473-487.

Stepp MA, Spurr-Michaud S, Tisdale A, Elwell J, Gipson IK (1990) $\alpha 6 \beta 4$ integrin heterodimer is a component of hemidesmosomes. Proc Natl Acad Sci USA 87:8970-8974.

Suzuki S, Naitoh Y (1990) Amino acid sequence of a novel integrin $\beta 4$ subunit and primary expression of the mRNA in epithelial cells. EMBO J 9.757-763.

Tamura RN, Rozzo C, Starr L, Chambers J, Reichardt LF, Cooper HM, Ouaranta $V(1990)$ Epithelial integrin $\alpha 6 \beta 4$ : complete primary structure of $\alpha 6$ and variant from of $\beta 4$. J Cell Biol 111:1593-1604.

Temple S, Raff MC (1985) Differentiation of a bipotential glial progenitor cell in single cell microculture. Nature 313:223-225.

Temple S, Raff MC (1986) Clonal analysis of oligodendrocyte development in culture: evidence for a developmental clock that counts cell divisions. Cell 44:773-779.
Wayner EA, Orlando RA, Cheresh DA (1991) Integrins $\alpha v \beta 3$ and $\alpha v \beta 5$ contribute to cell attachment to vitronectin but differentially distribute on the cell surface. J Cell Biol 113:919-929.

Wood PM, Bunge RP (1986a) Evidence that axons are mitogenic for oligodendrocytes isolated from adult animals. Nature 320:756-758.

Wood PM, Bunge RP (1986b) Myelination of cultured dorsal root ganglion neurons by oligodendrocytes from adult rats. J Neurol Sci $74: 153-169$

Wood PM, Williams AK (1984) Oligodendrocyte proliferation and CNS myelination in cultures containing dissociated embryonic neuroglia and dorsal root ganglion neurons. Dev Brain Res 12:225-241.

Zajicek J, Compston DAS (1994) Myelination in vitro of rodent dorsal root ganglia by glial progenitor cells. Brain 117:1333-1350.

Zeller NK, Behar TN, Dubois-Dalcq ME, Lazzarini RA (1985) The timely expression of myclin basic protein gene in cultured rat brain oligodendrocytes is independent of continuous neuronal influences. $\mathbf{J}$ Neurosci 5:2955-2962. 